\title{
AMIZADE E VIRTUDES NA CONSTRUÇÃO DE UMA IMAGEM IDEAL, ENCONTRADAS NO EPISTOLÁRIO CRUZADO ENTRE PLÍNIO, O JOVEM E O IMPERADOR TRAJANO (98 - 117 d.C.)
}

\author{
Thiago David Stadler. \\ Orientação: Renan Frighetto.
}

Palavras-Chave: Cartas de Plínio, o Jovem; Amizade; Virtudes.

O período que engloba o reinado dos Flávios e de Trajano ficou marcado na historiografia como aquele momento de máxima expansão territorial que o Império Romano já teve; por uma fase de esplendor da cultura e da língua de Roma e com o comércio atingindo níveis que em nenhuma outra época conseguiu. Como o próprio Ettore Paratore classificaria em sua obra "A História da Literatura Latina", este período oferece-nos enfim, "uma antecipação fiel do ideal da cultura clássica e da latinidade, como formou o

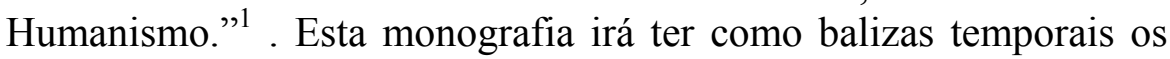
anos de 98 a 117 d.C, onde duas figuras marcaram presença na história do Império Romano com trajetórias diferentes, porém convergentes.

A primeira, um imperador marcadamente militar, nascido no município de Itálica - Hispania -, membro de uma família aristocrática e que desenvolveu uma brilhante carreira militar nos períodos de Domiciano ${ }^{2}$ (81-96 d.C) e Nerva (96-98 d.C). Estamos falando de Marco Ulpio Trajano, considerado como o primeiro imperador de origem provinciana, nascido em 18 de setembro de 53

\footnotetext{
${ }^{1}$ PARATORE, Ettore. A História da Literatura Latina. Firenze: Sansoni Editore, 1983, p. 681.

2 O governo de Domiciano foi marcado pela sua intolerância política, pela expulsão de filósofos e matemáticos de Roma e pelo seu caráter centralizador. Seu caráter absolutista rendeu comparações com Nero e Calígula, mas mesmo assim, sua habilidade governamental foi elogiada. In: BALSDON, J.P.V.D. O Mundo Romano. Rio de Janeiro: Zahar Editores:1965, p. 68.
} 
d.C, filho legítimo de Mario Ulpio Trajano - militar destacado do período de Vespasiano (69-79 d.C) - e filho adotivo do imperador Nerva $^{3}$. Seu governo assentou-se em um exercício militar e em um regime autocrático tendo como destaque, principalmente, as Campanhas contra os Dácios ${ }^{4}-101$ a 102 d.C e 105 a 107 d.C - e contra os inimigos tradicionais dos romanos, os partos -117 d.C. Entretanto não podemos ignorar as melhorias na agricultura, educação e em obras públicas que o governo de Trajano trouxe aos romanos. Como este soberano possuiu uma carreira militar, o apoio deste segmento mostrou-se de suma importância - notamos que houve uma legitimação pelo exército olhando para a aclamatio $^{5}$ pretoriana. Como sabemos, o imperador que conseguisse conciliar o segmento do exército com o Senado, teria o seu governo facilitado. Como no período de Trajano o Senado apresentava-se fraco, o imperador o tratou com respeito, mas adotou principalmente a postura de que "dando àqueles velhos rapazolas o acréscimo dum respeito formal com que a sua vaidade se possa ostentar satisfeita,

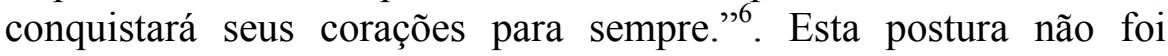
adotada num sentido de totalidade, pois esta monografia apresenta exatamente a relação entre um membro do Senado e o imperador Trajano, onde notamos um respeito mútuo e não um "descaso" por parte do soberano.

Dessa forma, passamos a apresentar este indivíduo que terá uma relação pessoal com o Imperador. Pertencente a uma família abastada foi responsável por escrever o único documento de oratória

\footnotetext{
${ }^{3}$ VEGA, María José Hidalgo de La. El Intelectual, la Realeza y el Poder Político en el Imperio Romano. Salamanca: Ediciones Universidad de Salamanca, 1995, p. 122.

${ }^{4}$ Esta Campanha foi proveitosa, visto que o terreno possuía destacada mina de ouro, mas sua posição estratégica era demasiadamente exposta, e a tornaria indefensável. In: BALSDON, op.cit., p.67.

5 Antes mesmo de se apresentar para o Senado, era costume receber a "aclamação" dos exércitos, fator este decisivo no governo dos imperadores. Neste caso, as tropas pretorianas obrigaram Nerva a nomear um general para assumir seu lugar.

${ }^{6}$ PARATORE, op.cit., p. 750.
} 
romana da primeira época imperial que chegou até nós ${ }^{7}$. Este jovem era Caio Plínio Cecílio Segundo, nascido na atual Itália por volta de 61/62 d.C, sobrinho e filho adotivo de Plínio, o Velho, por isso ficou conhecido com o epíteto de Plínio, o Jovem. Plínio começou seus estudos de retórica e leis com Quintiliano e Nicetas de Esmirna nesse período firmou amizade com Tácito - tendo em sua carreira a forte influência do primeiro $^{8}$ e uma branda interação com os vocábulos gregos - tentativa de imitar Cícero. Como estudou as leis, com dezoito anos iniciou a carreira de advogado tendo uma ascensão rápida, prova disto foi seu percurso no cursus honorum, pois no reinado de Domiciano ele começou como questor - cuidava do tesouro público - (91 d.C), no ano seguinte passou a Tribuno da Plebe e em 95 d.C a pretor - administrador da justiça.

Plínio se revela um intelectual porta-voz senatorial, que seguindo os ensinamentos de seu mestre Quintiliano, deveria se adaptar às necessidades do momento para ocupar postos de prestígio na administração do Estado. É dessa forma que nossos dois personagens - Trajano e Plínio, o Jovem - irão se cruzar no cenário político deste período (98-113 d.C) $)^{9}$, o primeiro um chefe militar e o segundo um aristocrata "pacífico". Esta relação possuiu particularidades interessantes, como a ampla troca de cartas entre Trajano e Plínio, o Jovem mostrando indícios de uma possível amizade entre ambos, ou tão somente uma postura adotada por intelectuais da época ${ }^{10}$. Entretanto, se esta era uma postura comum aos autores retóricos, o tempo não conservou outros escritos tão favoráveis como os de Plínio. Como exemplo, podemos usar a figura de Tácito, o qual mesmo sendo nomeado consul suffectus no período

\footnotetext{
${ }^{7}$ PARATORE, op.cit., p. 748.

${ }^{8}$ Quintiliano foi a maior influência de Plínio no que se refere ao jeito de elogiar, pelo gosto da moderação e da transparência - modelo de conduta cínico estóica. (VEGA, op.cit., p. 105).

${ }^{9}$ Esta datação não é da duração do reinado de Trajano, pois este se estende até 117 d.C. Esta data mostra o inicio do período de Trajano e a possível data de morte de Plínio o Jovem.

${ }^{10}$ VEGA, op.cit., p. 125.
} 
de Trajano ${ }^{11}$, apresenta uma desconfiança no futuro de Roma, devido a desvalorização dos antecedentes - visto que Trajano não era de origem italiana. Outro exemplo é o de Suetônio, o qual conseguiu através de Plínio, o Jovem - o ius trium liberorum no governo de Trajano e, mesmo assim não deixou relatos decisivos sobre este governo. Tudo isto mostra a particularidade da relação entre Plínio e Trajano, pois Tácito e Suetônio também pertenciam a mesma camada social que Plínio e nem por isso, deixaram testemunhos como os encontrados no nosso autor.

Buscando estas particularidades encontradas na relação entre Trajano e Plínio, o Jovem esta monografia utiliza como fonte primária as Cartas ou Epistolário de Plínio, o Jovem. Estas Cartas estão dispostas em nove livros compilados por Plínio e um livro compilado após a sua morte. É exatamente com este último livro Livro X - que busco informações sobre a amizade e sobre a construção idealizada de um soberano. Neste Livro X existem cento e vinte e quatro cartas, sendo setenta e três escritas por Plínio e cinqüenta e uma respostas de Trajano, trazendo informações de cunho político-administrativo, sociais e logicamente marcado pela presença das Virtudes. Para trabalhar sobre a questão da amizade e das Virtudes utilizei de alguns autores-chave, mas me ative fortemente na análise da fonte propriamente dita.

Ao estudarmos a construção da imagem dos imperadores - no caso deste trabalho a de Trajano - tendo como fundamento as Virtudes, temos que primeiramente buscar sentido e coerência no uso deste termo. Esta palavra deriva do latim Virtute, porém o "conteúdo", suas qualidades, são originariamente gregas, como aponta Manuel J. Rodríguez Gervás em seu texto Propaganda Política y Opinión Pública en los Panegíricos Latinos del Bajo Imperio, ao colocar que as Virtudes contém um profundo conteúdo moral-filosófico. Essa discussão acerca da natureza das Virtudes já havia sido posta por Aristóteles em Política, quando este entende que as Virtudes são um meio termo entre o vicio do excesso e o vicio da

${ }^{11}$ PARATORE, op.cit., p. 726. 
falta $^{12}$. Direcionando esta questão para o período que o trabalho preza - final do século I e inicio do século II - as Virtudes assumiriam basicamente dois intuitos: primeiro para glorificar o individuo, mostrando todas as suas qualidades e, por segundo, para contrapor o individuo "idealizado" a outro que deve ser diminuído. Usando da imagem construída por Plínio, o Jovem, do Imperador Trajano, nota-se que os dois intuitos das Virtudes são utilizados. Plínio irá realçar a superioridade de Trajano frente à Domiciano (8196 d.C) - este último considerado um déspota ${ }^{13}$ - e também exalta a figura benévola de Trajano, onde este soberano teria a formação ideal para um governante. Interessante notar que o imperador Trajano não apresentava características de cunho social/familiar que se enquadravam na dos imperadores anteriores.

Foi pesquisando sobre esta questão - características familiares de Trajano - que notei alguns motivos da boa relação entre o imperador e Plínio, o Jovem. Como vimos, o soberano veio de uma família marcadamente militar e o interessante é que Plínio, o Jovem também possuía uma ascendência na camada eqüestre. Além de ser um forte representante da camada senatorial, Plínio se apresenta como "amigo de origem" do imperador, o que dava um aumento de confiabilidade nesta relação. É claro que várias outras questões devem ser levadas em conta quando analisamos esta relação de amizade entre Trajano e Plínio, o Jovem. Com a análise das Cartas notamos que as relações entre os dois personagens só é possível se forem respeitadas a natureza dos laços políticos e sociais que envolvem o poder imperial. Esses laços são determinados pela capacidade material, intelectual e moral do homem político ${ }^{14}$ o que equivale a dizer, que Plínio não teria a "liberdade" que apresenta nas Cartas se não fosse pertencente ao círculo político pessoal de

\footnotetext{
${ }^{12}$ LEVORIN, Paulo. A República dos Antigos e a República dos Modernos. Tese (doutorado em Ciência Política). São Paulo: FFLCH/USP, 2001, p. 22.

${ }^{13}$ VEGA, op.cit., p. 116.

${ }^{14}$ VENTURINI, Renata Lopes Biazotto. As Palavras e as Idéias: o Poder na Antiguidade. Diálogos, DHI/PPH/UEM, v.9, n², 2005, p. 150.
} 
Trajano. Aqui é interessante apontar que um círculo pessoal político é muito diferente do que um círculo tão somente político, pois no período imperial as decisões eram tomadas no forum - um lugar público - por isso que a palavra "pessoal" ganha importância na discussão. Trajano buscava reuniões particulares para discutir política, colocando o forum "de lado", o que naturalmente fortalecia as relações entre os indivíduos dotados dos laços de confiança do imperador. É nesse ambiente que Plínio, o Jovem está inserido, onde a amicitia não é construída por acaso mas sim, fundada em deveres e obrigações variadas entre os membros.

Feita esta breve consideração acerca da "amizade" entre os personagens, voltamos para a relação que as Virtudes terão na construção de uma imagem idealizada. Esta monografia teve como premissa analisar a construção da imagem perfeita de Trajano a partir de duas virtudes: a Pietas e a Iustitia. A primeira das Virtudes de acordo com Manuel J. Rodríguez Gervás e Maria Helena da Rocha Pereira, assume basicamente duas qualidades: a primeira se refere à natureza das relações de pais e filhos ${ }^{15}$ também entendida como o sentimento de lealdade do cidadão com o governante, e a segunda converge na figura do soberano, sendo considerado um sentimento de dever e afeto deste para com os cidadãos ${ }^{16}$. Outra característica apontada para a Pietas é a de significar a origem do "acordo" entre os deuses e os Imperadores ${ }^{17}$. Esta Virtude foi analisada nesta monografia tomando como base as Cartas I, VIII e a IX do Livro X de Plínio, o Jovem. Nestas três Cartas podemos encontrar argumentos sólidos na análise da construção da imagem de Piedoso do imperador Trajano, visto que fora atendido a questão do "acordo

${ }^{15}$ PEREIRA, Maria Helena da Rocha. Idéias Morais e Políticas dos Romanos. In: Estudos de História da Cultura Clássica. Lisboa: Fundação Calouste Gulbenkian, p. 327.

${ }^{16}$ GERVÁS, Manuel J. Rodríguez. Propaganda Política y Opinión Pública en los Panegíricos Latinos del Bajo Imperio. Salamanca: Universidad de Salamanca, 1991. p. 79.

${ }^{17}$ GERVÁS, op.cit. 
divino ${ }^{18 \%}$ e também do sentimento de Dever para com seus súditos. Estes dois pontos se colocam como definitivo no fundamento de todas as boas relações do principado ${ }^{19}$.

A segunda Virtude analisada nas Cartas - Iustitia - também é pertencente a categoria de Virtudes Augustas (Virtus, Clementia, Iustitia e Pietas) e possuiu, basicamente, duas características definidoras. De acordo com Manuel Gervás a Iustitia é a Virtude por excelência do bom governante ${ }^{20}$, responsável pela qualidade em administrar com justiça ${ }^{21}$. A outra característica desta Virtude é a relação que esta propõe na diferenciação de um legitimo imperador do usurpador. Este segundo ponto ganha importância nesta monografia devido à caracterização e oposição que um usurpador possui em relação a um legitimo imperador. Maria Escribano em seu texto Usurpación y Religión en el Siglo IV d.C. Paganismo, Cristianismo y Legitimación Política, aponta que a figura do usurpator é importante para se contrapor a otimização do bom príncipe $^{22}$. Como este trabalho tem como objetivo a busca da idealização do soberano Trajano, notamos a importância que a Iustitia terá nesta construção otimizada por Plínio, o Jovem.

Antes de buscar e analisar esta Virtude nas Cartas trocadas entre Plínio, o Jovem e o imperador Trajano foi preciso fazer algumas considerações acerca de usurpação e legitimação, visto que um imperador legítimo e detentor da Iustitia busca dar aos seus

\footnotetext{
${ }^{18}$ Uma informação interessante é que este acordo divino era comemorado e reafirmado por todos os cidadãos na data simbólica de posse de Trajano - 27/28 de janeiro de 98 d.C -, sendo uma demonstração da pietas dos cidadãos - lealdade ao soberano - e envolvia um pedido para que a pietas do governante também se mantivesse. A Carta $\mathrm{C}$ mostra perfeitamente esta ação.

${ }^{19}$ GERVÁS, op.cit.

${ }^{20}$ GERVÁS, op.cit., p. 78.

${ }^{21}$ Iustitia é associada a outra virtude imperial, a Aequitas também definida como responsável da boa administração imperial.

22 ESCRIBANO, Maria Victoria. Usurpación y Religión en el S. IV D. de C. Paganismo,Cristianismo y Legitimación Política. Murcia: Universidad de Murcia. 1990, p. 248.
} 
cidadãos as concessões merecidas mas também se necessário, punir atos que tornariam perigosa a vida em sociedade. É aqui que não podemos confundir esta punição legítima com as atitudes que caracterizam um soberano usurpador. Estes abusam do poder para o bem próprio, buscando vantagens particulares nas relações públicas, sendo a punição utilizada para castigar indivíduos que não cooperam com as vontades do usurpador. Aqui é interessante integrar uma pequena discussão terminológica acerca da usurpação, pois no mundo imperial romano o vocábulo mais utilizado para definir aquele individuo que usa ilegitimamente o poder, era tyrannus ${ }^{23} \mathrm{e}$ não usurpator. Esta preferência pelo termo tyrannus é de influência grega, onde este assumiria um papel totalmente negativo, sendo possuidor da ira, violência, luxúria, avareza, impiedade, etc., e claramente se opondo a figura de optimus princeps. A análise da Iustitia foi feita utilizando as Cartas III-A, III-B, XXIX e LII, na quais pudemos notar a preocupação que Plínio, o Jovem demonstra nas questões político-administrativas, dando ao imperador Trajano uma posição de destaque nas decisões tomadas.

Após analisar todas estas Cartas buscando a possível construção idealizada do imperador Trajano é que ficam mais evidentes as questões sobre a relação pessoal entre Plínio, o Jovem e Trajano. Todo este enlace de Virtudes e Amizade nos leva a um questionamento: Trajano realmente seria capaz de ser detentor de tantas qualidades, Virtudes chegando a ser comparado com Augusto? Se olharmos as Cartas de Plínio, o Jovem não teremos dúvidas em responder que sim, pois a sua idealização se faz clara e acredito, que de forma consciente. Se lembrarmos que uma das funções das Virtudes é opor uma figura viciosa a uma otimizada e que, o governo de Domiciano ficou marcado negativamente, fica fácil imaginar as proporções que uma idealização da figura do próximo governante iria tomar. A personificação das Virtudes e a conseqüente exaltação da

\footnotetext{
${ }^{23}$ Outros termos relacionado com a tirania: latro, latrunculus, grassator, praedo, pirata, archipirata, defector, rebellis, perduellis, hostis. (ESCRIBANO, op.cit., p, 250).
} 
figura do Imperador coloca o soberano numa posição entre o divino e o humano, dando características sobrenaturais ao individuo ${ }^{24}$.

O que temos que entender é que Plínio, o Jovem era a favor de um governo autocrata - governo de um Príncipe, com poderes ilimitados e absolutos - que governasse em favor de benefícios para o Senado ${ }^{25}$. Com isso e com a sua formação baseada em Quintiliano, entendemos que esta construção idealizada pode ser interpretada com olhos de interesse particular - Plínio não iria assumir uma posição de dar opiniões contrárias as do soberano, pois isto poderia lhe custar "rachas" no seu cargo administrativo ${ }^{26}$. Também não podemos ignorar neste momento, a postura que o imperador Trajano teve em relação a Plínio, o Jovem, mostrando sempre uma cooperação com as petições de cunho pessoal. Como vimos, a amizade entre ambos mostrou um imperador disposto a atender aos pedidos e a exigir as obrigações que os laços pessoais colocavam nesta relação entre os dois. Não fica difícil de imaginar que Plínio, o Jovem poderia adotar em sua forma de escrever, uma postura de propagador da "boa política" de Trajano, fortemente influenciado pelo laço de amizade entre os dois. Dessa forma, acredito que mais do que "idealizarem", as Virtudes se mostraram como "propagandas políticas" favoráveis ao governo de Trajano. Pois ao notar que os dois personagens estão inseridos numa conduta em que os indivíduos perseguem objetivos em comum, adquirem dignidade e respeito mútuo, comportando-se de maneira responsável ${ }^{27}$, concluímos que a exaltação das Virtudes e a relação pessoal de amizade tendem a adquirir uma legitimidade social e política.

\footnotetext{
${ }^{24}$ VEGA, op.cit., p. 109.

${ }^{25}$ VEGA, op.cit., p. 119.

${ }^{26}$ VEGA, op.cit., p. 128.

${ }^{27}$ DAHL, Robert A. A Moderna Análise Política. Rio de Janeiro: Editora Lidador Ltda, 1966, p. 34.
} 